\title{
Research Paper \\ The efficacy of positive couple therapy and treatment based on acceptance and commitment on the desire for divorce
}

Bonyad Jamshidzehi' Farhad Kahrazei $^{\mathbf{2}}$, Mahmoud Shirazi
1. Ph.D Student of General Psychologyt, Faculty of Psychology and Educational, Department of Psycholog, Zahedan Branch, Islamic
Azad University, Zahedan, Iran.
2. Associate Professor, Faculty of Educational and Psychology, Department of Psychology, University of Sistan and Bluchestan,
Zahedan, Iran.

Citation: Jamshidzehi B, Kahrazei F, Shirazi M. The efficacy of positive couple therapy and treatment based on acceptance and commitment on the desire for divorce. J of Psychological Science. 2021; 20(106): 1881-1895.
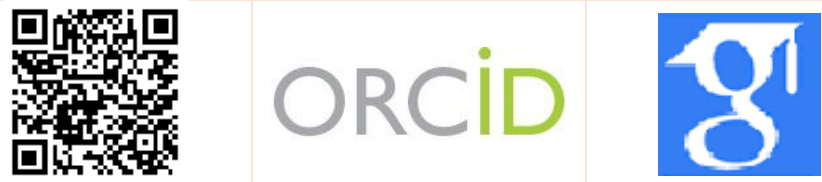

URL: https://psychologicalscience.ir/article-1-1197-fa.html

$\underline{10.52547 / J P S .20 .106 .1881}$

\section{A R T I C L E I N F O A B S T R A C T}

Keywords:
Positive
Therapy,
Acceptance $\quad$ and
Commitment
Divorce,
Couple

Received: 28 Mar 2021 Accepted: 22 Apr 2021 Available: 22 Dec 2021
Background: Research has shown that positivist psychotherapy leads to marital adjustment and a reduction in the desire for divorce in couples. On the other hand, acceptance and commitment therapy has been effective in reducing issues such as conflict and conflict, adaptation and commitment means having a rich and meaningful life, but there is a research gap in comparing the two approaches. Aims: The aim of this study was to evaluate the effectiveness of positive couple therapy and treatment based on acceptance and commitment on reducing the desire for divorce in couples.

Methods: The method of the present study was quasi-experimental with a pretest-posttest design with a control group in. The statistical population included all couples seeking divorce who had referred to Iranshahr family counseling centers in 2020 for couple therapy. 45 couples were selected by convenience sampling method and then randomly divided into two groups of 30 experimental and one group of 30 controls. Participants responded to the Roosevelt, Johnson \& Moro (1986) Divorce Desire Questionnaire. Couples therapy training - Positive Seligman and Csikszentmihalyi (2000) and therapy based on acceptance and commitment Hayes, Strosahl and Wilson (2012) in 8 sessions of 90 minutes on the experimental groups and after the post-test sessions Done. Finally, after the post-test, the results were analyzed by analysis of covariance.

Results: The results showed that couples therapy, positive therapy and treatment based on acceptance and commitment were effective in reducing the desire for divorce in couples $(\mathrm{P}<0.01)$. Also, positive couple therapy training had a more significant effect than acceptance and commitment therapy (P $<0.01)$.

Conclusion: Considering that both interventions had a strong effect on reducing the desire for divorce, but positive couple therapy was more effective in reducing the desire for divorce and negligence, so the combination of these two methods in couple therapy interventions will probably lead to more effective results.

* Corresponding Author: Farhad Kahrazei, Associate Professor, Faculty of Educational and Psychology, Department of Psychology, University of Sistan and Bluchestan, Zahedan, Iran.

E-mail: farhad_kahraz@ped.usb.ac.ir

Tel: (+98) 9124106246

2476-5740/ @ 2021 The Authors. This is an open access article under the CC BY-NC-ND license

(https://creativecommons.org/licenses/by-nc/4.0/). 


\section{Extended Abstract}

\section{Introduction}

Divorce is a multi-factor phenomenon that has destructive effects on the individual and the family and cause a variety of anomalies in the social dimension (Shahmoradi, Sadeghi, Goodarzi and Roozbehani, 1398). Divorce is one of the most important family traumas that leads to individual, family and social collapse (Narimani, Rahimi and Sedaghat, 1397) and is strongly associated with increasing psychological problems and declining social and economic status for all people involved (Khojastehmehr, Mohammadi, Sudani and Abbaspour, 1397). In order to improve couples' relationships, various approaches have been developed, one of which is positive couple therapy, which is one of the psychoanalytic approaches that, by identifying the inner psychological domains of each spouse, also analyzes how to create a common tissue. Far et al., 1399). Seligman and Seixent Mihali (2000) believe that positive psychology seeks to improve the quality of life of individuals and prevent the psychological damage caused by a fruitless and meaningless life (Flanagan, Joseph, Nitrite, Beck and McCrady, 2019). Teaching couples the concepts of positive psychotherapy also leads to more agreement with their spouse and increases satisfaction with the relationship with the spouse (Jangabreli et al., 2018). The second coupltherapy approach that has been studied in this study is acceptance and commitment based therapy. Acceptance and commitment therapy was introduced in 1986 Hayes as a useful way to help improve a couple's relationship. In fact, the basic structure and concept of the commitment and acceptance approach is that psychological suffering and reflection are created by avoiding experiences, intertwined cognitions, and failing to meet behavioral needs and not conforming to core values (Hayes, Strosahl and Wilson, 2012). In a study, no significant difference was observed between positive cognitivebehavioral therapy and commitment-based therapy and acceptance (Kiani et al., 1399). A study of external studies comparing positive couple therapy with acceptance and commitment therapy was not found. Considering the importance of identifying different treatments and determining the effectiveness of each of these psychological therapies, the main purpose of this study is to compare the effectiveness of positive couple therapy and treatment based on acceptance and commitment to the desire for divorce.

\section{Method}

The present study was a quasi-experimental design with pretest-posttest with a control group. The statistical population included all couples seeking divorce who had referred to Iranshahr family counseling centers in 2020 for couple therapy. 45 couples were selected voluntarily as a sample and then the sample was randomly divided into experimental group (30 couples) and control group (15 couples). Fifteen couples in the experimental group were trained in positive couple therapy and acceptance and commitment therapy. Divorce questionnaire was administered to all couples before the intervention. The purpose of the sessions was to increase the decrease in the desire for divorce in couples. The sessions were conducted in the form of questions and answers and group discussions, and homework presentation, and then the workshop was conducted by the researcher. First, a pretest was performed, then the experimental group received 8 sessions of positive couple therapy, 8 sessions of acceptance and commitment therapy, and each session lasted 90 minutes (two sessions per week) for both treatments. At the end of the sessions, a post-test was conducted by the Divorce Desire Questionnaire. The instrument used in this study was Roosevelt, Johnson \& Moro (1986) Divorce Desire Questionnaire, first designed by Roosevelt et al. In 1986. The short form of this scale is a 14-item tool used to assess gifted couples seeking divorce. This questionnaire was administered by Davoodi, Etemadi and Bahrami (1390) in Iran to 40 couples. Its reliability was calculated using Cronbach's alpha for the whole sample of 0.88 ( 0.89 for women and 0.87 for men) and Cronbach's alpha for the subscales of inclination to exit 0.89 and tolerance to 0.88 . The validity of the questionnaire was assessed in the form of content analysis by five psychologists and counselors, the validity of which was obtained. According to the pre-test-post-test design with the 


\section{Monthly Journal of Psychological Science}

control group, Mankova and Bonferroni tests were used to analyze the data. Data analysis was performed using Spss-26 statistical software.

\section{Results}

The results showed that there was a significant difference between the experimental and control couples in the tendency to separation, the tendency to negligence and the overall score of reducing the desire for divorce by controlling the pretest. In other words, the training of positive couple therapy and treatment based on acceptance and commitment according to the average tendency to divorce, tendency to carelessness and the overall score of divorce in the experimental group compared to the average of the control group, increases the tendency

Table 1. Summary of the difference between the means and dimensions of reducing the desire for divorce between the experimental and control groups

\begin{tabular}{lccc}
\hline & I & J & I-J \\
\hline \multirow{2}{*}{$\begin{array}{c}\text { Tendency to separate or } \\
\text { divorce }\end{array}$} & $\begin{array}{c}\text { Positive couple therapy } \\
\text { Acceptance and commitment } \\
\text { treatment }\end{array}$ & Control & -19.51 \\
& Positive couple therapy & Control & -7.05 \\
& Positive couple therapy & Acceptance and commitment \\
treatment & Control & -12.50 \\
Tendency to be careless & treatment & Control & 6.12 \\
& Positive couple therapy & Acceptance and commitment & treatment \\
Total Divorce Reduction & Positive couple therapy & Control & -2.98 \\
Score & Acceptance and commitment & Control & $3.63-$ \\
& Preatment & Acceptance and commitment \\
treatment & -3.20 \\
\hline
\end{tabular}

\section{Conclusion}

The results of differential studies indicated that positive couple therapy had a significant effect on reducing the desire for divorce in couples referring to counseling centers. Therefore, it can be expected that this approach can be well and completely useful and effective in the field of divorce-related problems in couples, which is fully confirmed by the results of the present study. These results are consistent with the results of previous research in this field.

The results of separate studies on acceptance and commitment treatment showed that this treatment had a significant effect on reducing the desire for divorce in couples referring to counseling centers. By reviewing theoretical perspectives and examining to negligence and decreases. The tendency to separate and the desire to divorce the group has been tested. Comparison of the two groups in terms of scores for reducing the desire for divorce shows that the difference between the mean scores of the dimensions of reducing the desire for divorce (tendency to divorce and tendency to negligence) in group therapy showed positive couple therapy, between the effectiveness of positive couple therapy and treatment Based on acceptance and commitment, there is a significant difference between the experimental and control groups based on the degree of desire for divorce, tendency to negligence and the overall score of reducing the desire for divorce in the post-test phase (Table1).

various texts, it can be seen that the treatment of acceptance and commitment, using the skills of mindawareness, acceptance and cognitive failure seeks to achieve psychological flexibility. This treatment focuses on more flexible and adaptive ways of responding to unpleasant internal stimuli. Therefore, it can be expected that the treatment of acceptance and commitment, which seeks to increase the flexibility of individuals, can be effective in reducing the desire for divorce, which has been the case. These results are consistent with the results of previous research in this field.

Finally, the desire for divorce has been considered not only as a common phenomenon; rather, it is of special importance due to its high prevalence among couples 
in society. Therefore, it is important for psychopaths to be armed with methods of treatment and control of this factor. Overall, it can be concluded that both treatments had a significant effect on the desire for divorce and its components. Therefore, due to the clinical importance of the desire for divorce, further research in this area is necessary and inevitable.

One of the most important limitations of the present study, which limits the generalizability of its results, is the number of samples under study and the limited sample to Iranshahr city counseling centers.

It is suggested that the effectiveness of different treatments in treating couples and reducing the desire for divorce and the factors affecting it should also be considered. Based on the results of the present study, we will find that both the therapeutic approach of positive couple therapy and acceptance and commitment are effective in controlling and treating the desire for divorce. Therefore, the techniques of each of the two therapies proposed based on the therapist's expertise can be used to treat the desire for divorce.

\section{Ethical Considerations}

Compliance with ethical guidelines: This article is extracted from the doctoral thesis in psychology of Zahedan Azad University, which was conducted in accordance with the principles of research ethics.

Funding: This study was conducted as a $\mathrm{PhD}$ thesis with no financial support.

Authors' contribution: The first author was the student and senior author, the second were the corresponding author and supervisors and the third was the advisors.

Conflict of interest: The authors declare no conflict of interest for this study.

Acknowledgments: I would like to appreciate the participants who contributed to this research. 


\section{اثربخشى زوجدرمانى مثبتنكر و يذيرش و تعهد بر ميل به طلاق}

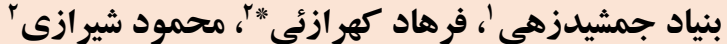

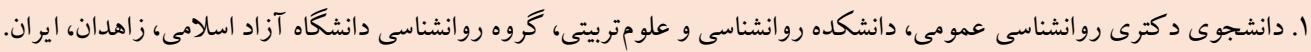

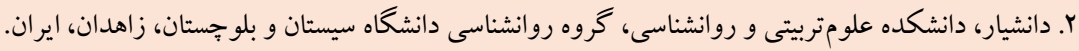

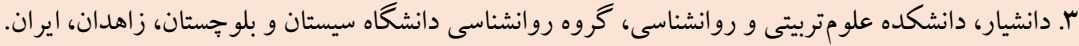

زمينه: تحقيقات نشان داده است رواندرمانى مثبت گرا به ساز گارى زناشويى و كاهش ميل به طلاق در زوجين منجر مىشود. از سوى ديخر درمان مبتنى بر بذيرش و تعهد در كاهش مواردى همجيون كشمكش و منازعه، ساز گاى و تعهد به معناى داشتن زندگ بوده است اما در زمينه مقايسه اين دو رويكرد شكاف تحقيقاتى وجود دود دارد. هدف: هدف اين يزوهش مقايسه اثر بخشى زوجدرمانى مثبتنكر و درمان مبتى بر بذيرش و تعهل بر كاهش ميل به طلاق در زوجين بود. روش: روش يُزوهش حاضر از نوع شبه آزمايشى باطرح ييش آزمون - يّ آزمون با گروه گواه بود. جامعه آمارى شامل كليه زوجين خواهان

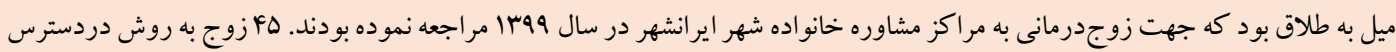
به عنوان نمونه انتخاب شدند و سبس به طور تصادفى در دو گروه .ب نفرى آزمايش و يكك گروه .ب نفرى گواه تقسيم شدند. شركت

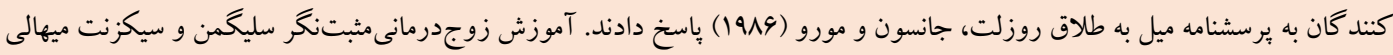

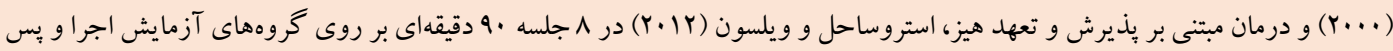

از اتمام جلسات يس آزمون انجام شد. در يايان بعد از اجر ایى بس آزمون نتايج با آزمون تحليل كوواريانس مورد تحليل قرار گرفت. يافته ها: نتايج نشان داد آموزش زوجدرمانىمثبتنگر و درمان مبتى بر يذيرش و تعهد در كاهش ميل به طلاق در زوجين مؤثر بوده است

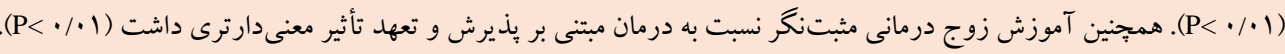

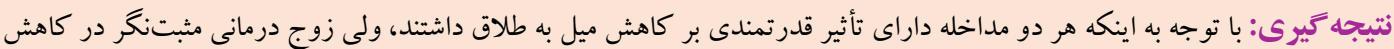
ميل به طلاق و مسامحه مؤثرتر بود لذا تركيب اين دو روش در مداخلات زوج درمانخرى احتمالا به نتايج مؤثرترى منتج مى گردد.
مشخصات مقاله

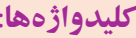

زووجدرمانى مثبتنگر،

درمان مبتى بر يذيرش و تعهد،

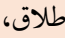

زوجين

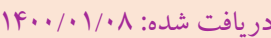

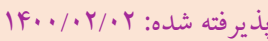

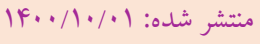

* نويسنده مسئول: فرهاد كهرازئى، دانشيار، دانشكده علومتربيتى و روانشناسى، گروه روانشناسى دانشگاه سيستان و بلوجستان، زاهدان، ايران.

farhad_kahraz@ped.usb.ac.ir رايانامه

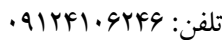


در يزوهشى با عنوان "آموزش زوجدرمانى مثبتنخر با رويكرد شناختى رفتارى بر افزايش كيفيت زندكى و شاد كامى زوجين" نشان دادند كه

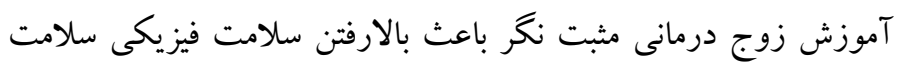

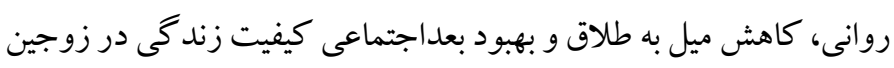

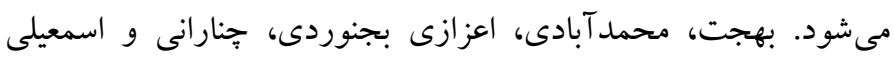

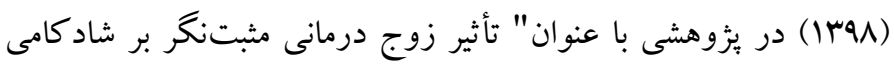

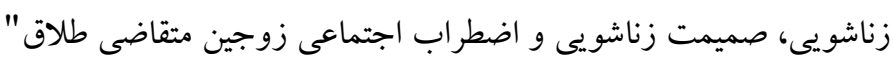

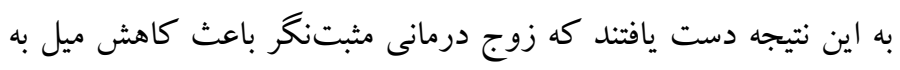

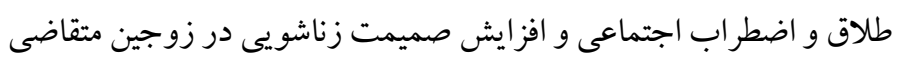
طلاق مىشود. در يزوهشى تحت عنوان "بهبود روابط بين والدين در هنگك هنگك با توجه

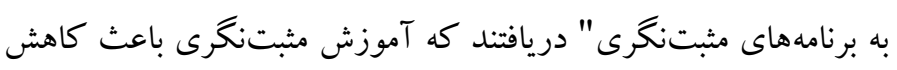

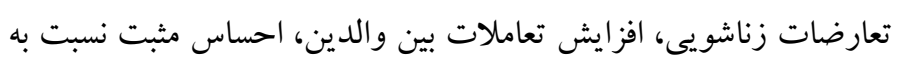

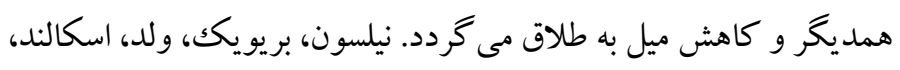

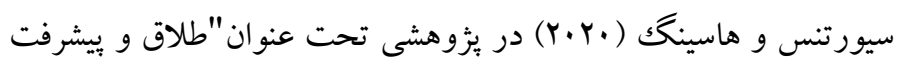

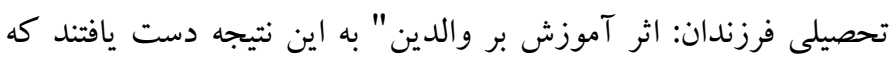

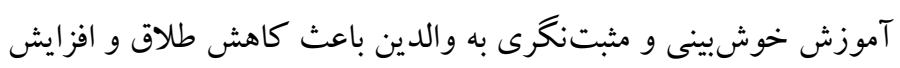

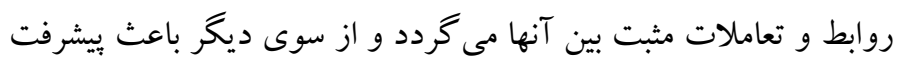

$$
\text { تحصيلى فرزندان مىشود. }
$$

دومين رويكرد زوج درمانى كه در اين يزوهش برونى فردى شده است درمان مبتنى بر يذيرش و تعهد است. درمان مبتنى بر يذيرش و تعهد توسط هيز

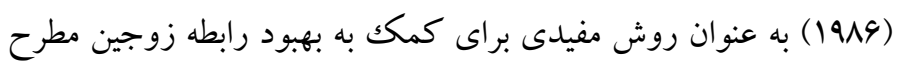

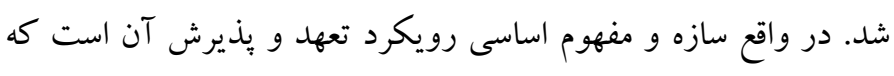

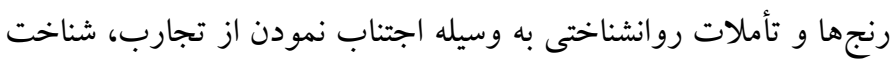
هاى در هم تنيده و شكست در بر آورده كردن نيازهاى رفتارى و تطبيق نيافتن با ارزش هاى اساسى ايجاد مى گر ددد (هيز، استروساحل و ويلسون،

درمان مبتنى بر ويذيرش و تعهد '، مشكلات زناشويى را به گونهاى متفاوت

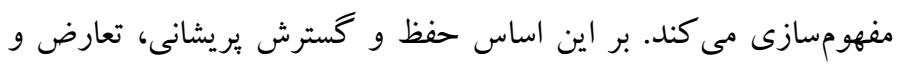
فاصله عاطفى ميان زوجين از تركيب راهبردهاى كنترل و اجتناب تجربى بـ إنى

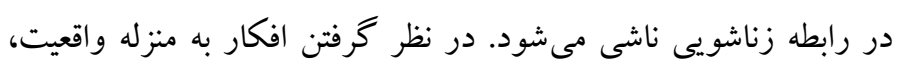

مقاله

طلاق، بديدهاى جند عاملى است كه بر فرد و خانو اده آثار مخربى دارد و

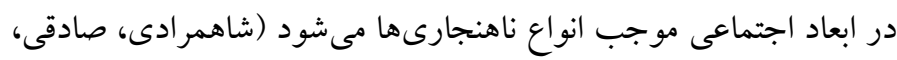

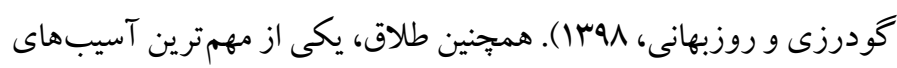

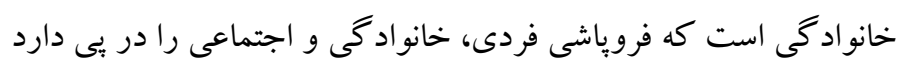

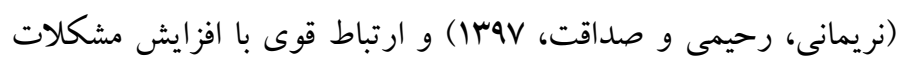
روانى و افت موقعيت اجتماعى و اقتصادى براى همه افراد دركير دارد وداني

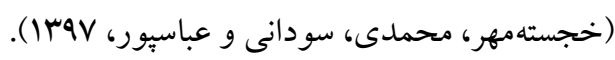

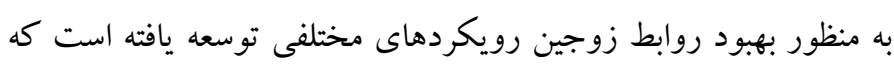

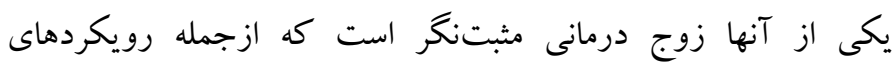

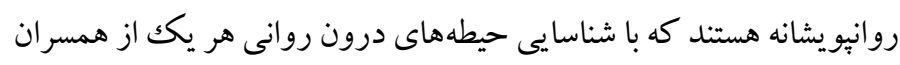

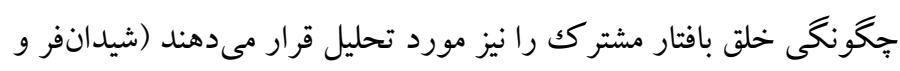

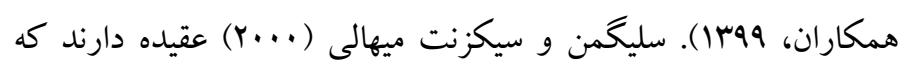

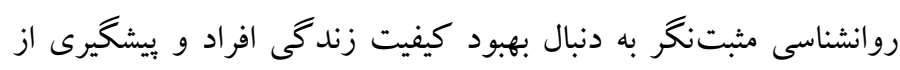

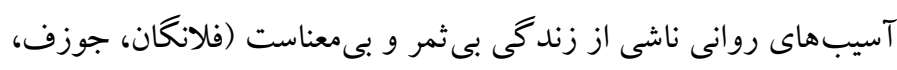

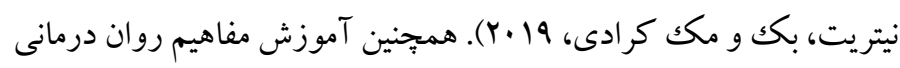
مثبتنكر به زوجين منجر به توافق بيشتر آنها با همسرشان مى مود و و رضايت

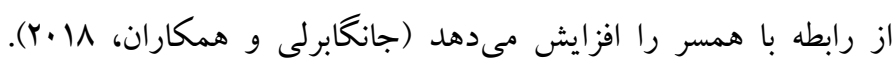

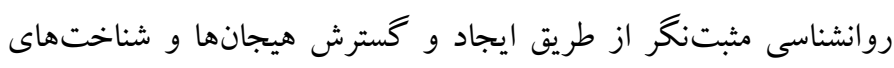

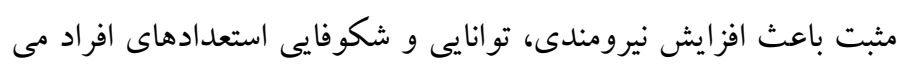

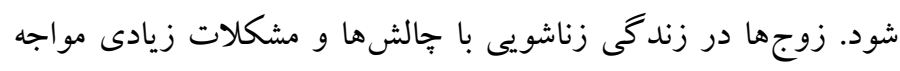

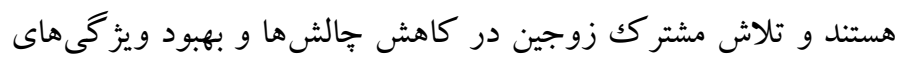

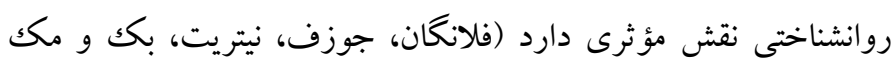

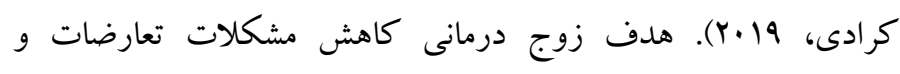

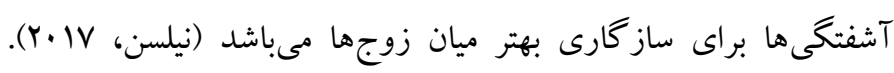

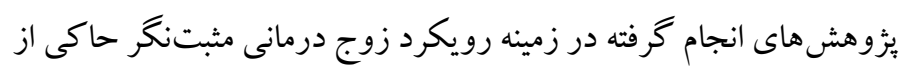

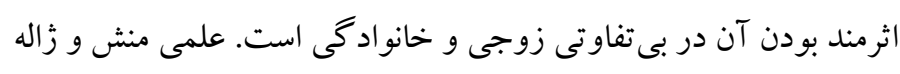
(ITqV)

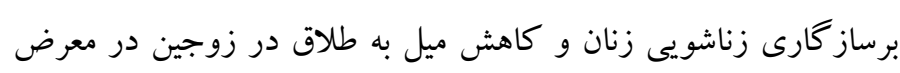
طلاق شهر اصفهان مؤثر است.

1. Acceptance and Commitment based Therapy 
(ها زوج) و گروه درمان مبتنى بر يذيرش و تعهد (ها زوج) و گروه گواه

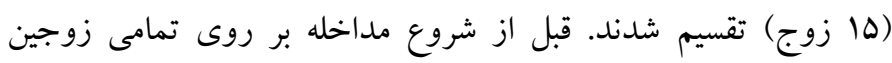

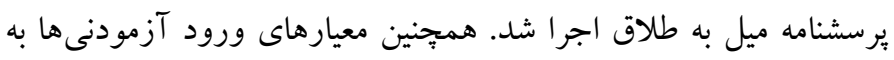

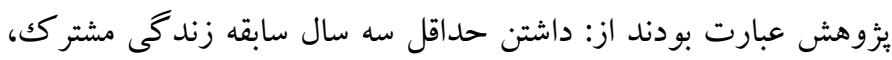
حضور هر دو عضو در جلسات درمانى، مشاركت و انجام فعاليتهاى داده

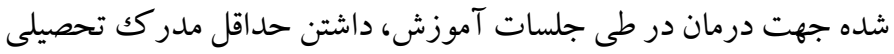
سيكل، دامنه سنى •ه-DQ سال، متقاضى طلاق نبودن، تكميل فرم رضايت نامه درمان و عدم دريافت مشاوره فردى در طول شر كت در جلسات درمان و معيارهاى خروج مشتمل بر عدم رعايت هر يكك از شر ايط ورود به مطالعه،

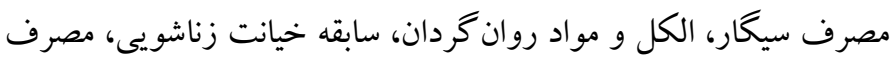

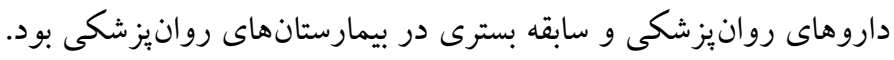

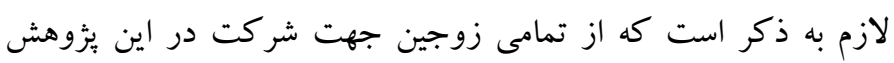

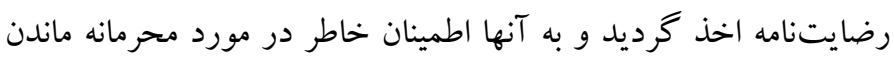
اطلاعات و تحليل دادهها به صورت گروهى داده شد. در اين بزوهش جهت جمع آورى دادهها از برسشنامه ميل به طلاق روزلت،

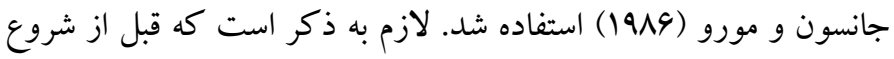
يُزوهش براى رعايت ملاحظات اخلاقى، درباره اهداف يُزوهش و نحوه رعايت اصول رازدارى توضيحات لازم به افراد داده شد و به آنها تأكيد مهيد

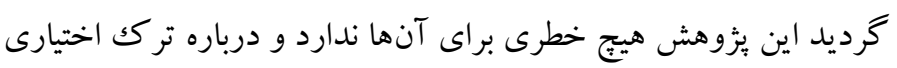
يُزوهش در هر زمان كه مايل باشند توضيحاتى به آنها داده شد و بعد از

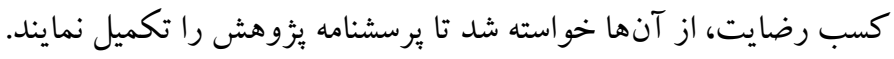
روش كار به اين صورت بود كه بعد از هماهنكى با مراكز مشاوره خانو اده

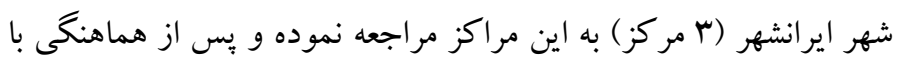
اين مراكز و انتخاب زوجين در مورد اهداف يزوهش و اهميت آن توضيح داده شد. سبس فرم رضايت به صورت آكاهانه و كتبى توسط زوجين جهت شركت در بزّوهش تكميل و به آنها تأكيد شد هر زمان مايل نبودند مى توانند از يزوهش خارج شوند و همجنين در مورد محرمانه ماندن

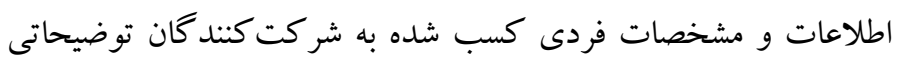
ارائه كرديد. هدف جلسات، كاهش ميل به طلاق در زوجين بود كه

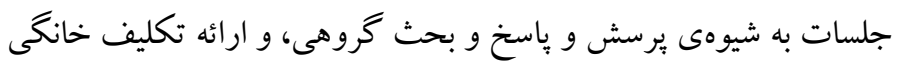

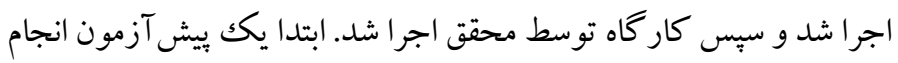

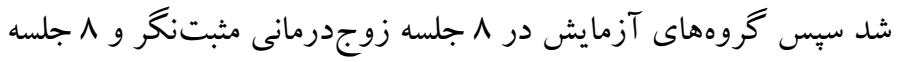

ارزيابىهاى منفى گرايانه و عمل كردن بر طبق آنها موجب حفظ خرخه

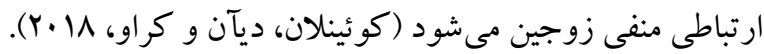

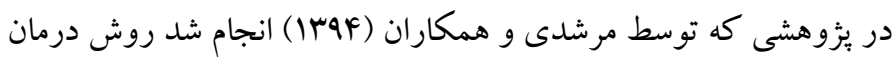

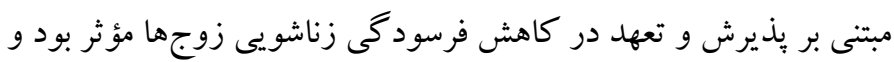
تحقيقات زيادى جنين نتيجهاى را نشان دادند. در بزوهشهايى زيادى در ايران به كاربرد دو روش درمانى مثبتنغر و و

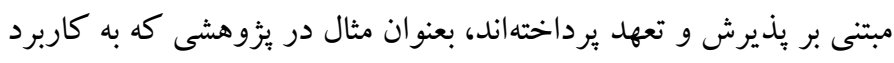

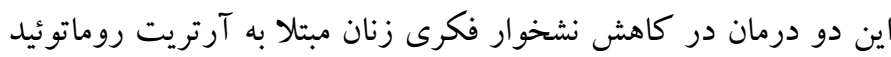

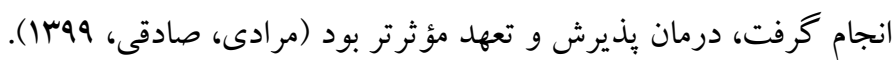

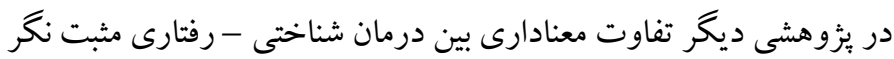

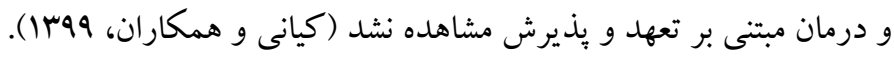
همجنين كاربرد اين دو درمان براى افزايش بهزيستى روانشناختى زنان

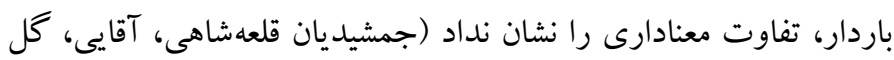
يرور، هوس1). اين دو روش درمانى در مقالات متعدد خارجى به تنهايى و

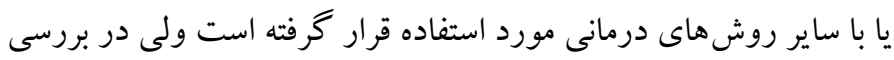

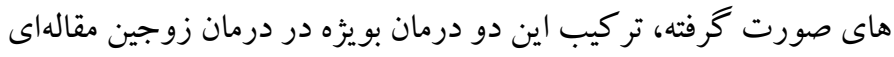
يافت نشد، از اين رو تركيب اين دو روش درمانى در كاهش ميل به طلاق ترد

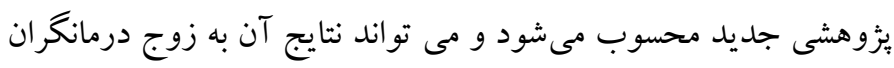

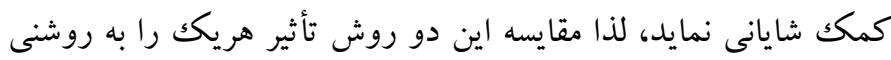
مشخص مىنمايد. بر اين اساس هدف اصلى اين يُزوهش بررسى مقايسه

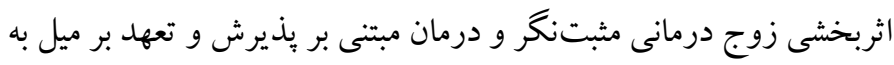

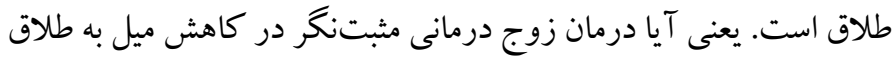
از درمان بذيرش و تعهد مؤثرتر است؟ آيا اين درمان در مقايسه با درمان دمان ديخر بهتر عمل مى كند.

روش

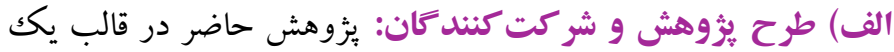

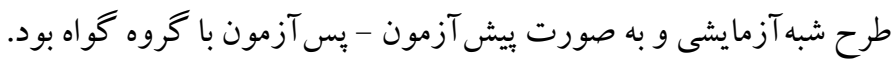

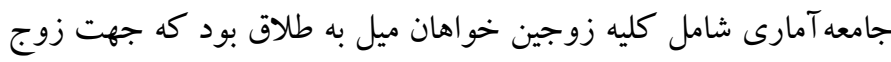
درمانى به مراكز مشاوره خانو اده شهر ايرانشهر در سال 99جا مر اجعه نموده

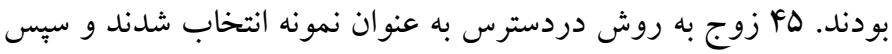
نمونه به طور تصادفى در دو گروه آزمايش (كروه زوج درمانى مثبت نخر 


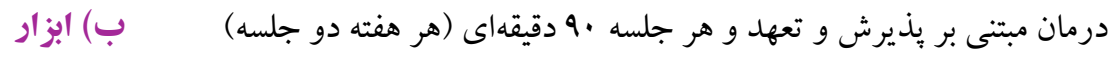
يرسشنامةٔ ميل به طلاق روزلت، جانسون و مورو (1919): اين مقياس اولين بار توسط روزولت و همكاران در سال 1919 طر احى شده است. فرم كو تاه براى هر دو درمان دريافت كردند. بِ از بايان جلسات يكك بـ بـ آزمون توسط برسشنامه ميل به طلاق انجام شد.

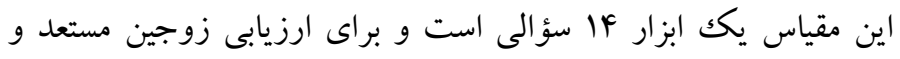

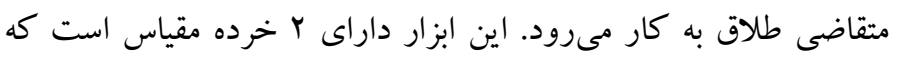
هر كدام توسط V سؤال مورد سنجش قرار مى گيرد. خرده مقياس ها شامل: تمايل براى خارج شدن (تمايل به طلاق) و عدم تمايل به مسامحه مىباشد.

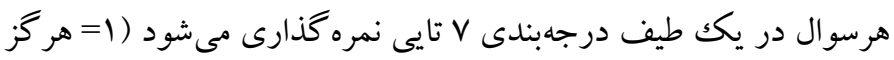

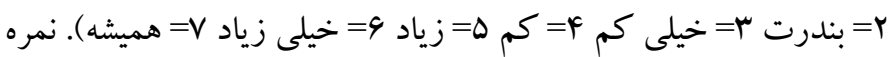
اين برسشنامه با جمع سؤ ال بدست مى آيد. به عبارتى كمينه و بيشينه نمرهها

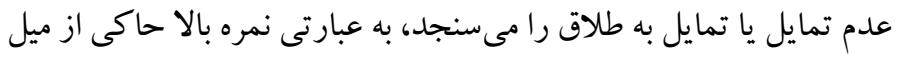

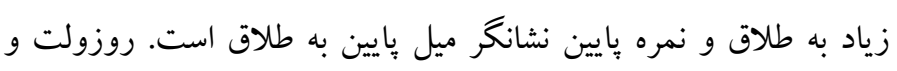

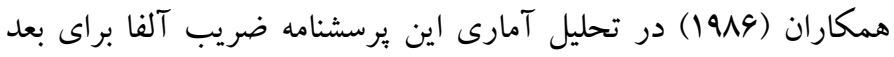

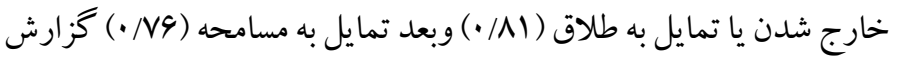

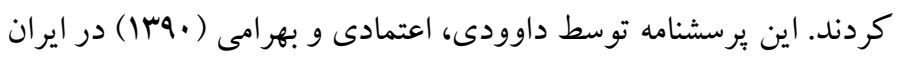

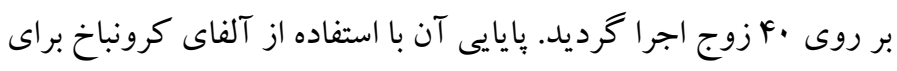

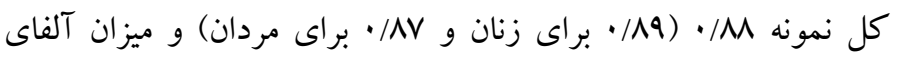

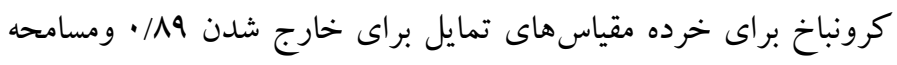

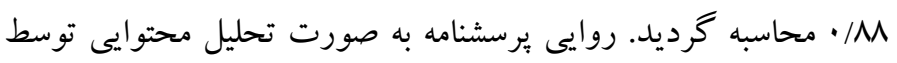
ينج نفر از متخصصين روانشناسى و مشاوره بررسى شده است كه روايى آن مناسب بدست آمده است.

قبل از انجام مداخله يرسشنامه ميل به طلاق در اختيار آزمودنىها قرار

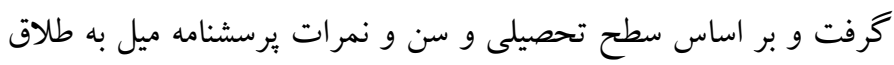

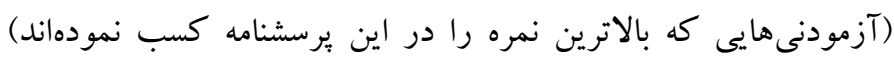

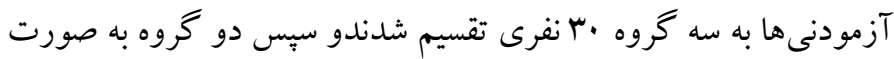

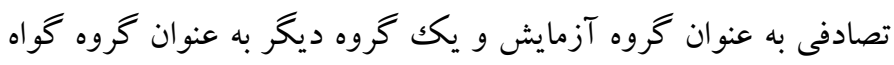
انتخاب شدند. محتوا و اهداف جلسات بر گرفته و گسترش يافته از ديد كاه

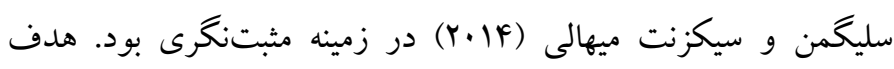

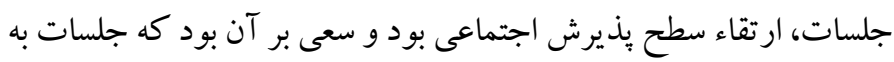

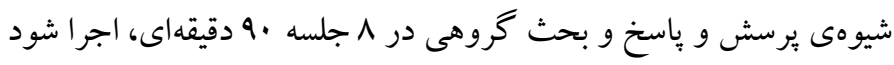

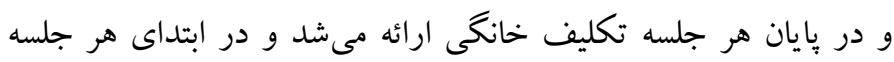
تكاليف و مباحث جلسه قبل بررسى مىشد (جدول (1). همجنين درمان

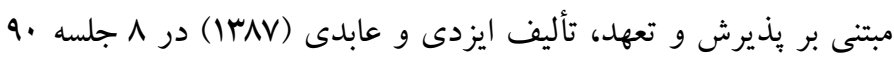

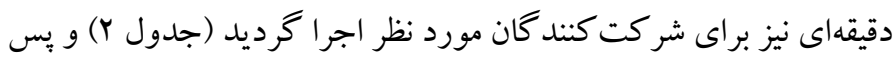
از پايان جلسات يكك پِ آزمون انجام شد. جهت توصيف دادهها از شاخصهاى آمار توصيفى (فراوانى، درصد، آنماند

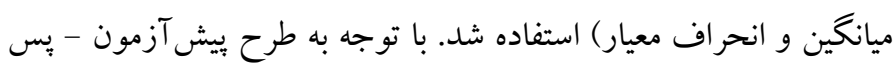

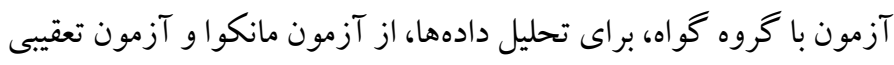
بنفرونى استفاده شد. تحليل دادهها با استفاده از نرمافزار آمارى انجام گرفت.

جدول ا. يرو تكل جلسات آموزشى درمان مبتنى بر روانشناسى مثبتنكر (سليعمن و سيكزنت ميهالى، ... (؟)

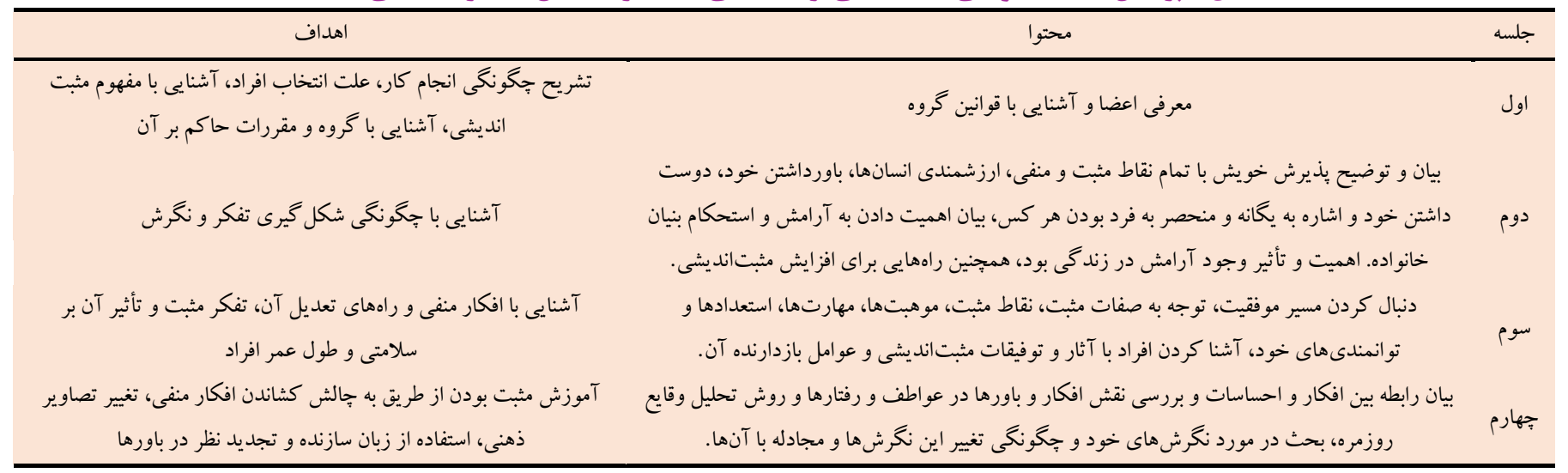




\begin{tabular}{|c|c|c|}
\hline اهداف & محتوا & جلسه \\
\hline 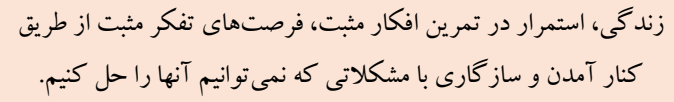 & 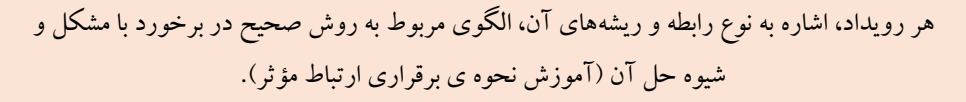 & ينجم \\
\hline 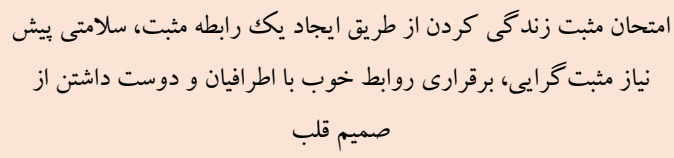 & بررسى شوخطبى به عنوان يكك نياز وجودى انسان، تمرين خوش خينى، بررسى آثار و نتايج كمكك و & ششم \\
\hline مثبت بودن از طريق آموزش شيوه توقف فكر، آرامسازى و تغيير نخرشها الزام، مهار كردن و مبارزمطلى & ماهيت صميميت و راههاى شاد زيستن و رهنمودهايى براى افزايش صفا و صميميت & هفتم \\
\hline وارد كردن خنده به زندگى، ايجاد اعتماد بنفس و ايجاد عادت مطلوب & 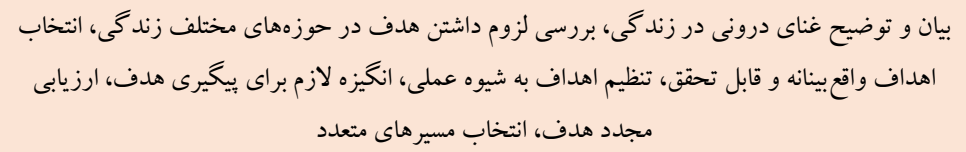 & هشتم \\
\hline
\end{tabular}

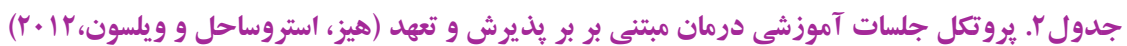

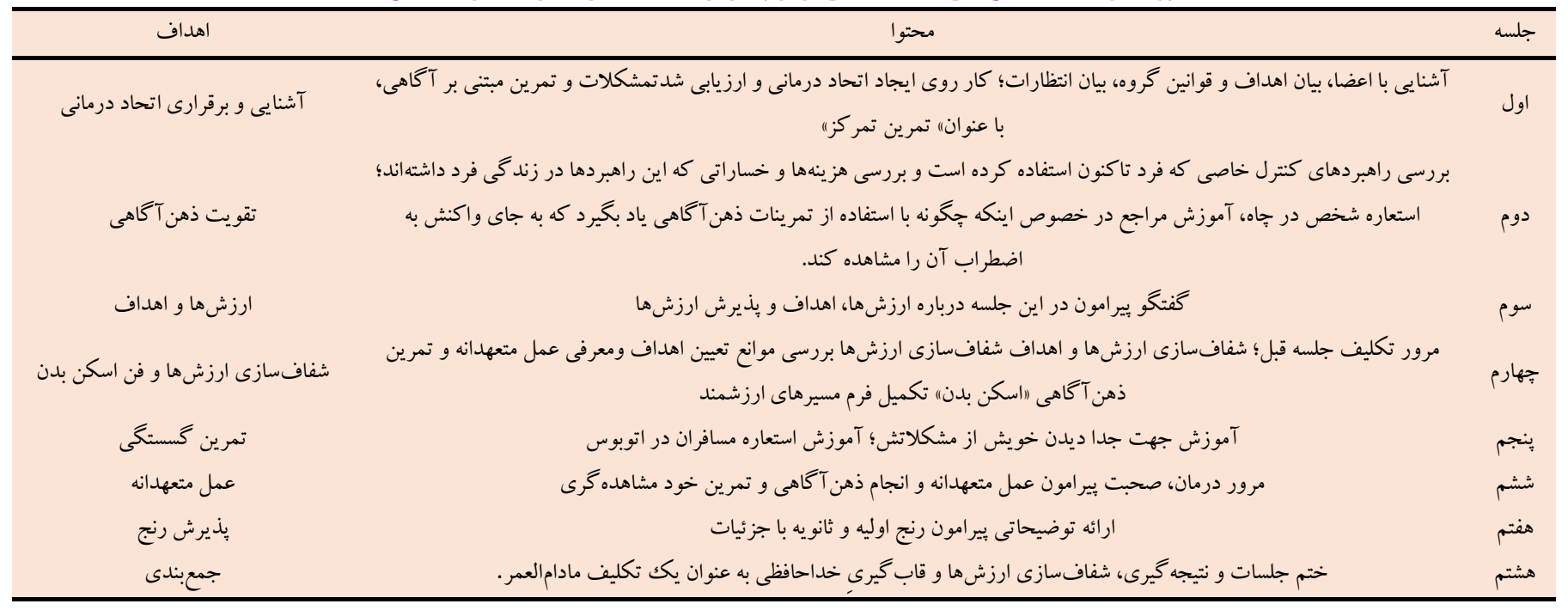

جدول ץ آمارههاى توصيفى متغيرهاى مورد مطالعه به تفكيك كروه ها در بيش آزمون و يس آزمون ارائه شده است. ابتدا يِيشفرض نرمال بودن توزيع متغيرهاى وابسته با استفاده از آزمون شاييرو و ويلك در آموزش زوج درمانى مثبتنگر و آموزش مبتنى بر يذيرش و تعهد بررسى و تأييد شد.

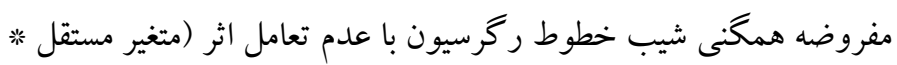
بيش آزمون) در آموزش زوج درمانى مثبتنگرو آموزش مبتنى بر يذيرش و تعهد بررسى و تأييد شد. به عبارتى تعامل بين اثراصلى كروه با بيش

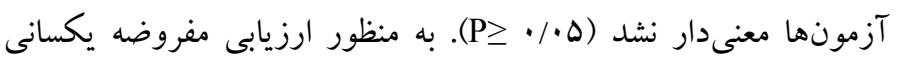
واريانسهاى خطا از آزمون لون استفاده شد و سطح معنادارى بالاتراز ينج

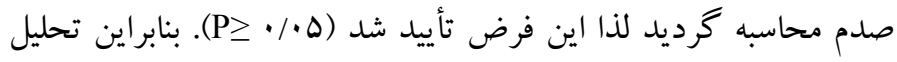

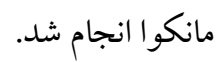

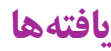
بررسى اطلاعات دمو گر افيك آزمودنى ها نشان داد كه نمونه شامل ·9زوج

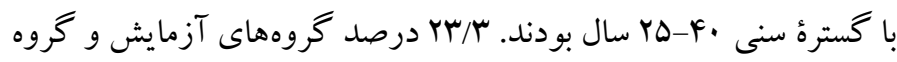

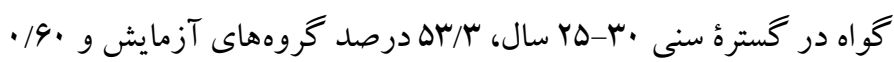

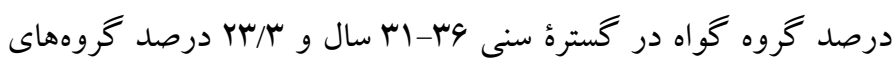
آزمايش و گواه در كستره سنى

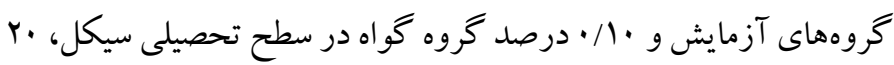

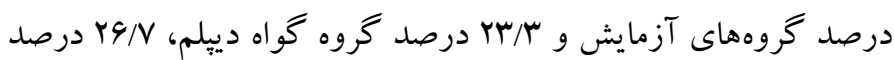

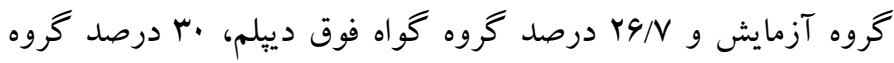

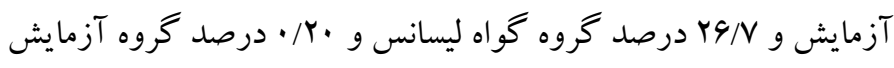
و س/ ا درصد گروه گو اه در سطح تحصيلى فوق ليسانس قرار داشتند. در 
جدول ب. ميانكين و انحر اف استاندارد نمرات كاهش ميل به طلاق در كروههاى آزمايش و كنترل

\begin{tabular}{|c|c|c|c|}
\hline يس آزمون & ي بيش آزمون & \multirow{2}{*}{ 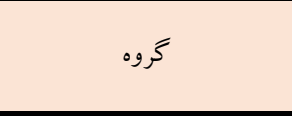 } & \multirow{2}{*}{ متغير } \\
\hline ميانگين (انحر اف استاندارد) & ميانگين (انحر اف استاندارد) & & \\
\hline $19 / \pi / \mu / F / \mu \cdot)$ & $r V / 9 \cdot(r / r r)$ & زوج درمانى مثبت نگر & \\
\hline$r Y / / T(F / .4)$ & $r q / r \cdot(r / \cdot r)$ & درمان مبتنى بر بذيرش و تعهد & تمايل به جدايى يا طلاق \\
\hline$r q / \cdots(V / \& q)$ & $M F / r q(9 / 91)$ & 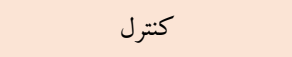 & \\
\hline$F \cdot / A r(r / \& q)$ & $r V / F q(Y / Q \Delta)$ & زوج درمانى مثبت نگر & \\
\hline$r N / q r(Y / F V)$ & $\Pi r / 9 \cdot(r / \mu)$ & درمان مبتنى بر پذيرش و تعهد & تمايل به مسامحه \\
\hline$r \Delta / N r(r / q 4)$ & $\boldsymbol{H N / Q Y}(Y / F V)$ & 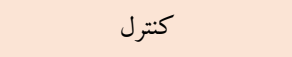 & \\
\hline $9 \cdot / 19(F / \mu)$ & $V \Delta / \cdot q(F / q \cdot)$ & زوج درمانى مثبت نخر & \\
\hline$V \backslash / \cdot q(F / l \cdot)$ & $V \cdot / l \cdot(\kappa / M \Lambda)$ & درمان مبتنى بر يذيرش و تعهد & نمره كل كاهش طلاق \\
\hline$V I / N r(V / \Delta \Lambda)$ & $V \Psi / r \cdot(\xi / V \Delta)$ & كنترل & \\
\hline
\end{tabular}

\begin{tabular}{|c|c|c|c|c|c|c|c|c|}
\hline تو ت ت ان آزمون & اندازه اثر & سطح معنادارى & $\mathrm{F}$ & ميانگين مجذورات & درجات آزادى & مجموع مجذورات & متغير & \\
\hline 1 & $\cdot / \mathrm{VA}$ & $\cdot \cdots \cdot 1$ & $109 / 4 T$ & rVr. 199 & r & $\Delta F F I / / N$ & تمايل به جدايى يا طلاق & \\
\hline 1 & $\cdot 109$ & $\cdot / \cdots 1$ & $9 Y / r \wedge$ & Mrr/ra & r & $994 / 09$ & تمايل به مسامحه & كروه \\
\hline 1 & $\cdot 191$ & $\cdot \cdots 1$ & $Q Y / Y F$ & $1909 / .4$ & r & MTIN/9 & نمره كلى كاهش ميل به طلاق & \\
\hline - & - & - & - & $\mid V / r q$ & $\Lambda \Delta$ & IFVN/TF & تمايل به جدايى يا طلاق & \\
\hline- & - & - & - & $\Delta / r r$ & $\Lambda \Delta$ & Far/Vr & تمايل به مسامحه & خطا \\
\hline- & - & - & - & $\mid V / 9 \Lambda$ & No & $|D Y N / V|$ & نمره كلى كاهش ميل به طلاق & \\
\hline - & - & - & - & - & 9. & ArVI9/.. & تمايل به جدايى يا طلاق & \\
\hline- & - & - & - & - & 9. & $|r F V| q / \cdot$. & تمايل به مسامحه & كل \\
\hline - & - & - & - & - & 9. & FIVIAV/.. & نمره كلى كاهش ميل به طلاق & \\
\hline
\end{tabular}

ابعاد كاهش ميل به طلاق (تمايل به طلاق و تمايل به مسامحه) در گروه

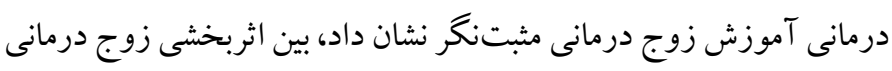

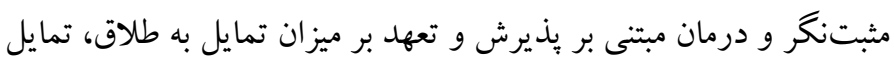

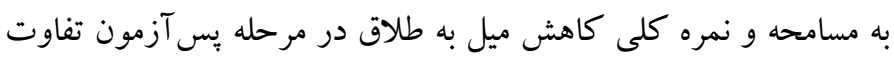
معندارى بين گروه آزمايش و كنترل وجود دارد.
بنابر اين تحليل مانكوا انجام شد. در جدول \& نتايج بر روى ميانخين نمرات

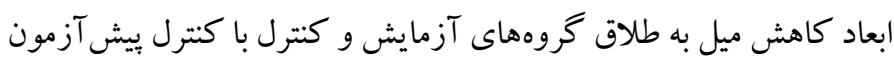

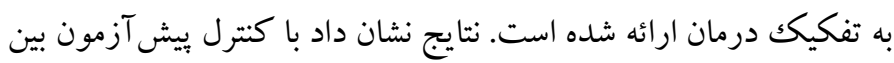

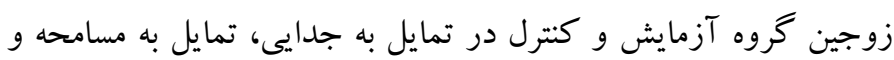
نمره كلى كاهش ميل به طلاق تفاوت معنىدارى وجود دارد. به عبارت

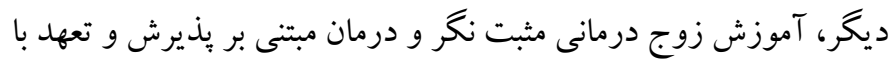

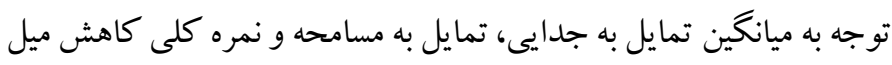

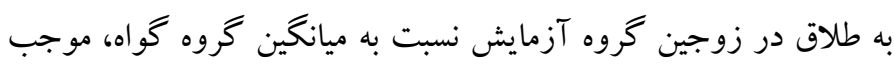
افزايش تمايل به مسامحه وكاهش تمايل به جدايى و ميل به طلاق گروره آزمايش شده است. در جدول ها مقايسه زوجى گروههاى آزمايش و گو اه يس آزمون ارائه شده -

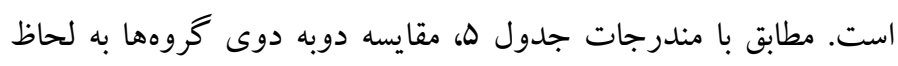

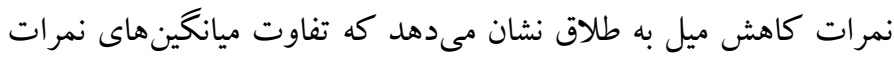


جدول ه. خلاصه نتايج آزمون بنفرونى در مورد تفاوت ابعاد كاهش ميل به طلاق دو كروه آزمايش و كنترل

\begin{tabular}{|c|c|c|c|c|}
\hline سطح معنادارى & تفاوت ميانگينها & (J) كروه & (I) & متغيرها \\
\hline$\cdot / \cdots 1$ & $-19 / 81$ & كنترل & زوج درمانى مثبتنخر & \\
\hline$\cdot / \cdots \cdot 1$ & $-\mathrm{V} / \cdot \cdot \Delta$ & 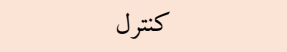 & درمان متنى بر يذيرش و تعهد & تمايل به جدايى يا طلاق \\
\hline$\cdot / \cdots 1$ & $-1 Y / 0$ & درمان متنى بر يذيرش و تعهد & زوج درمانى مثبتنخر & \\
\hline$. \cdots+1$ & $9 / 1 \mathrm{r}$ & 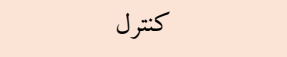 & زوج درمانى مثبتنخر & \\
\hline$\cdot / \cdots 1$ & $\mathrm{~V} / \mathrm{II}$ & 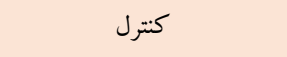 & درمان متنى بر يذيرش و تعهد & تمايل به مسامحه \\
\hline.$/ 1$ & $-r / 9 \Lambda$ & درمان متنى بر يذيرش و تعهد & زوج درمانى مثبتنخر & \\
\hline.$/ \cdot 1$ & $-r / \mu q$ & 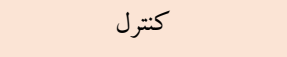 & زوج درمانى مثبتنخر & \\
\hline$\cdot / \cdot 1$ & $-r / r$. & 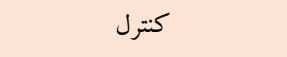 & درمان متنى بر پذيرش و تعهد & نمره كلى كاهش ميل به طلاق \\
\hline$\cdot / \cdots 1$ & $-1 \% / 49$ & درمان متنى بر يذيرش و تعهد & زوج درمانى مثبتنخر & \\
\hline
\end{tabular}

متون مختلف مىتوان دريافت كه درمان بذيرش و تعهل، با استفاده از

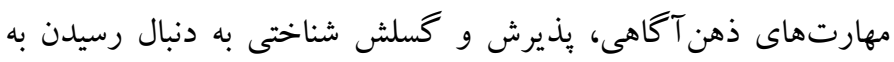

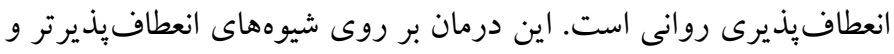

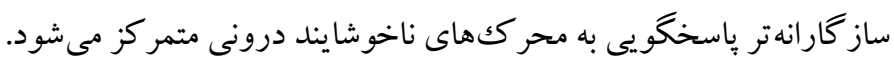

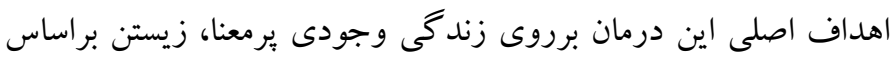

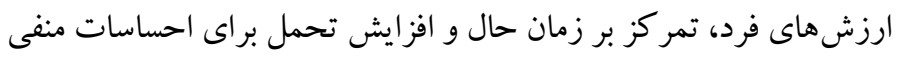

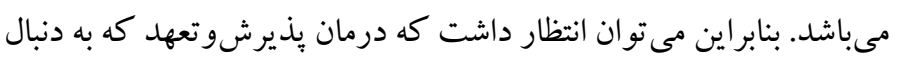

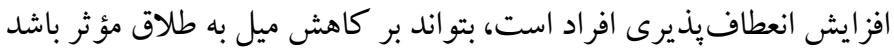

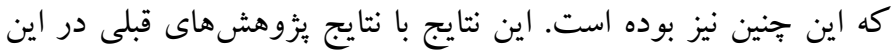
حوزه همخوانى دارد (فراهانىفر و همكاران، لوجا!؛ اعلمى و همكاران،

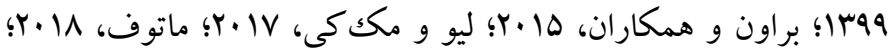

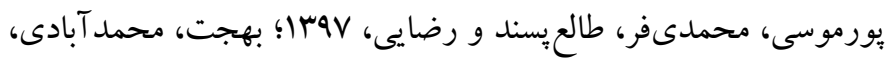

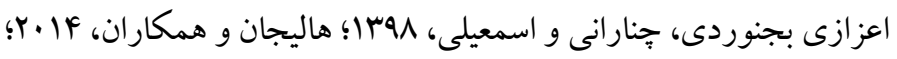

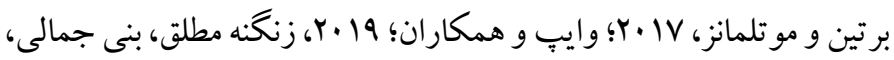
احدى و حاتمى، 94 (1). باتوجه به نتايج به دست آمده در جدول ه كه به مقايسه بس آزمون گرووهها

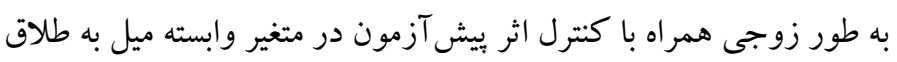

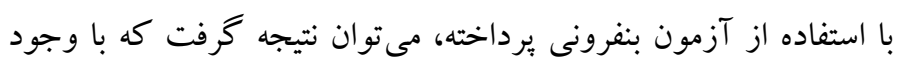

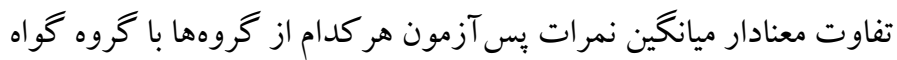

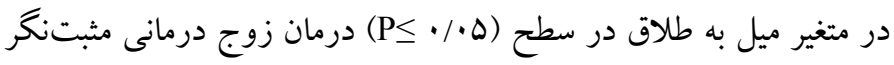
در مقايسه با درمان يذيرش و تعهد اثربخشى بالاترى داشته است كه اين

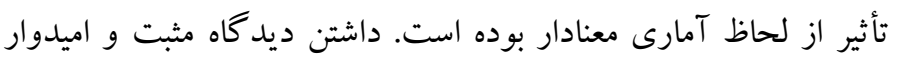

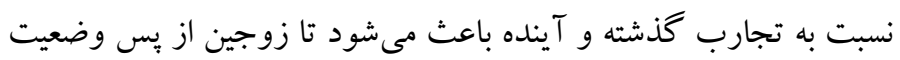

بحث و نتيجه تيرى

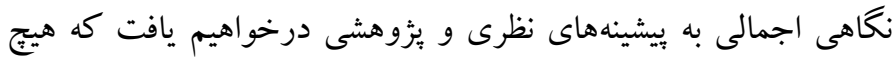

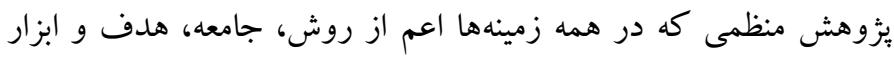

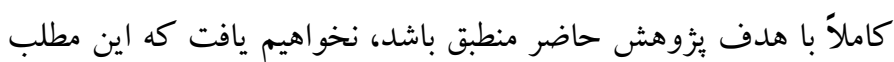
خود، ضرورت و اهميت انجام يُزوهش حاضر را خاطر نشان مىسازد.

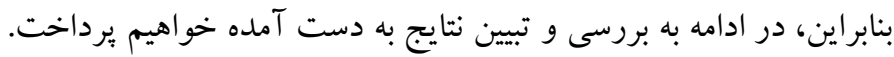

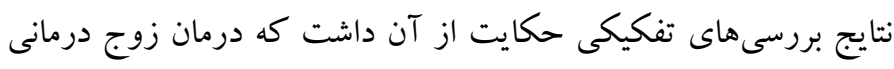
مثبتنكر بر كاهش ميل به طلاق در زوجين مراجعه كننده به مراكز مشاور

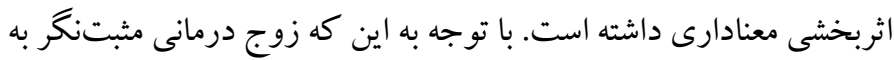

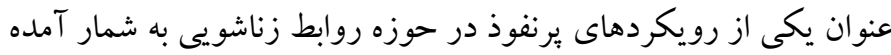

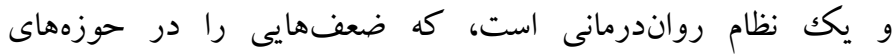

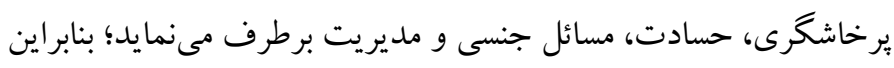

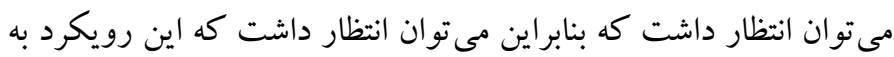

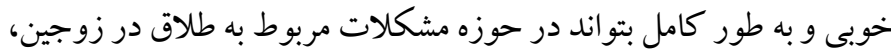
مفيد و مؤثر واقع شود كه اين مسأله با توجه به نتايج يثوهش حور حاضر، كاملاً

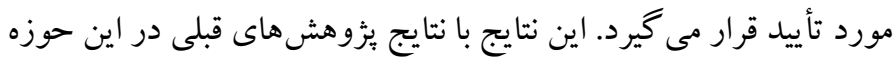

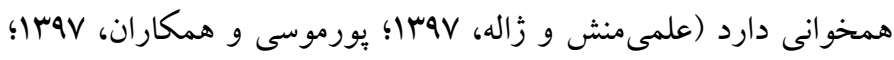

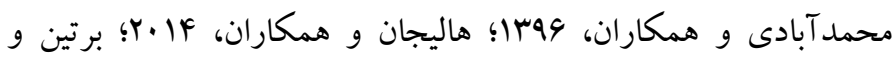

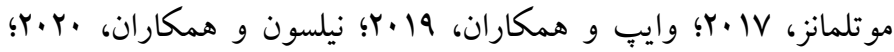

$$
\text { زاركوسكى و بريس، (Y) (Y) (1). }
$$

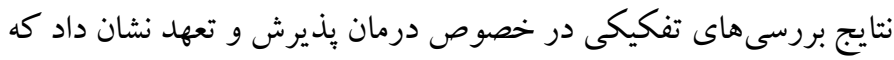

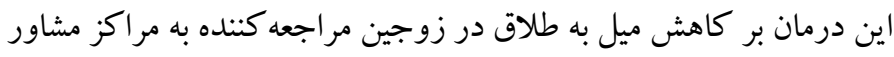

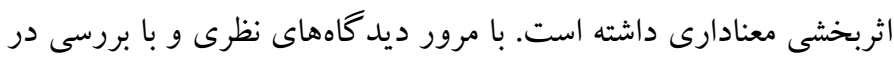


يا بين زوجى، ممكن است زوج ها عوامل فشار زاى بيرونى مختلفى را بر

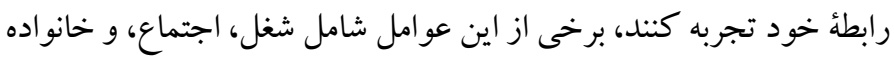
كسترده مىباشد. سخن آخر اين كه ميل به طلاق، نه تنها به عنوان يكك بديده شايع مورد

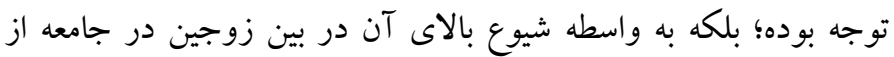

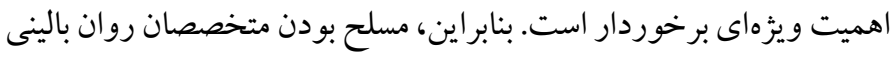
بر شيوههاى درمان و كنترل اين عامل، از اهميت به سز ايى برخوردار است.

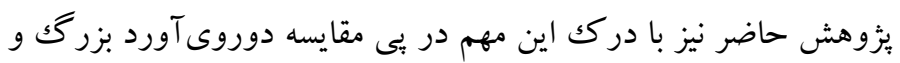

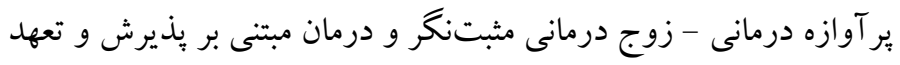

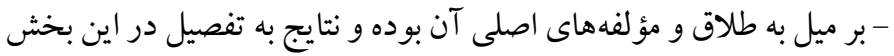

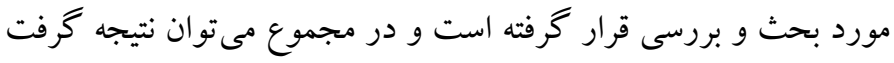
كه هر دو درمان اثربخشى معنادار بر ميل به طلاق و مؤلفه هاى آن داشته

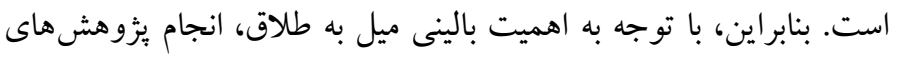

$$
\text { بيشتر در اين حوزه ضرورى و اجتنابنايذير است. }
$$

يكى از مهمترين محدوديت هاى بزوهش حاضر كه تعميميذيرى نتايج آن را محدود مى سازد تعداد نمونه مورد مطالعه و محدود بودن نمونه به مراكز

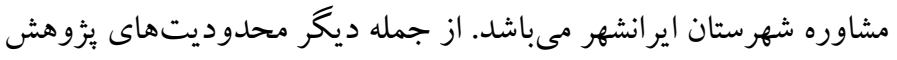

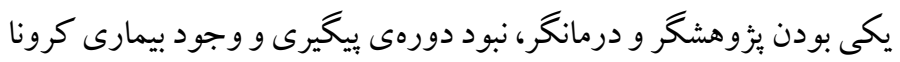
بوده است. با توجه به محدوديتهاى به وجود آمده در يُزوهش حاضر، يِينهادات

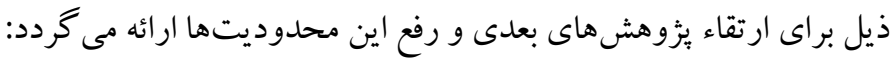

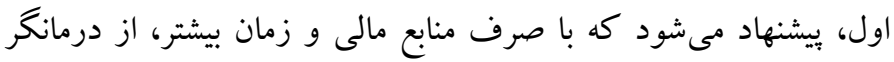
مجزايى (غير از بثزوهشخر) جهت انجام و بيخيرى درمان استفاده گردد تا بـاني

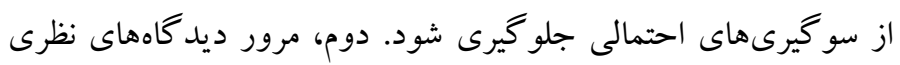
خاطر نشان كرد كه درمانها از نظر تنوع، وسعت زيادى ديرى دارند؛ بنابراين بيشنهاد مى گردد تا اثربخشى درمانهاى مختلف در درمان زوجين و كاهش ميل به طلاق و عوامل مؤثر بر آن نيز مورد توجه قرار گيرد. سوم، در نهايت توصيه مىشود كه مقايسه و اثربخشى اين دوشيوه درمان، به عنوان يرجمداران درمانها، برروى ساير عوامل مؤثر بر طلاق يا مشكلات

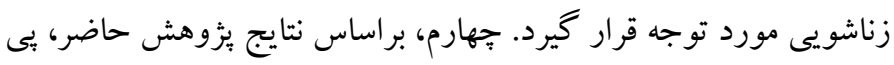

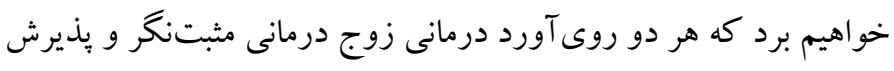

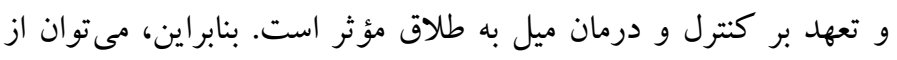

هاى نامساعد بر آمده و از هر موقعيت يكك موفقيت بسازند. در واقع مثبت انديشى به افراد كمكك مى كند تا به امور مثبت زندگى توجه داشته بـ باشند و به جنبههاى منفى آن توجه نداشته باشند كه داشتن اين ديدكاه در نتيجه

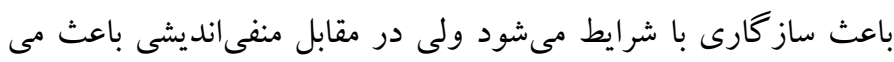
شود كه زوجين فقط به جنبه هاى منفى زند

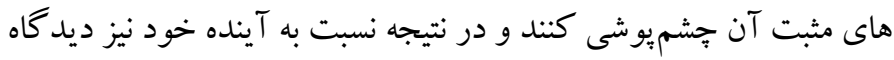

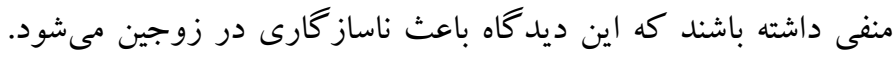

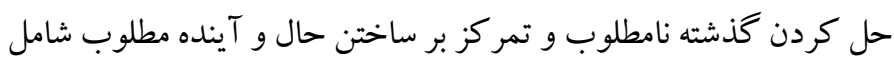
در لحظه زندگى كردن، تمركز زدايى از كذشته، تركى رابطه ناكار آمد،

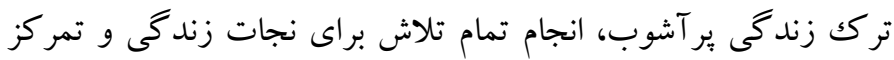

$$
\text { برساختن آينده مطلوب است. }
$$

با مرور ديد كاههاى نظرى در مى يابيم كه يكى از مشكلات تهديد كنتده

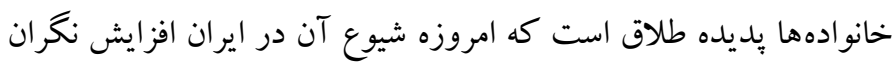
كنندهاى داشته است. در بررسى علت طلاق توجه به علل فردى و روانشناختى از جمله ميل به طلاق از اهميت ويزهاى برخوردار است

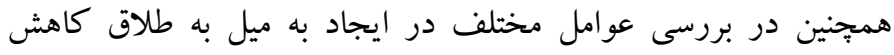

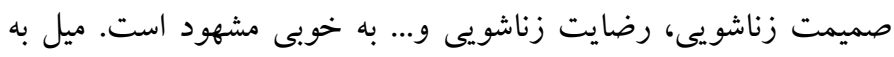

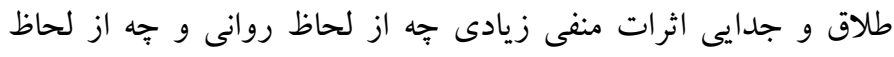

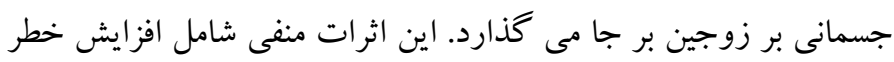

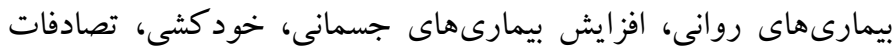

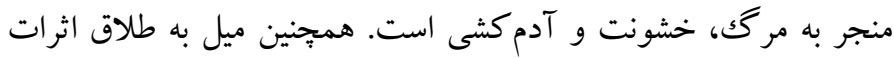

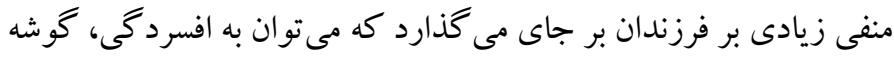
كيرى، ضعف كفايت اجتماعى، مشكلات بهداشتى و تحصيلى اشاره كرد. تصميم به طلاق و ميل به آن در نتيجه فشار درونى شديدى است كه حداقل به يكى از همسران وارد مى شود كه ممكن است از طريق بر آورده نشدن

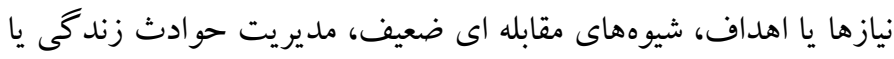

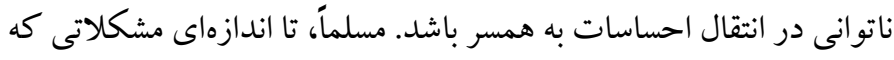
سبب مىشود، زوجين تصميم به جداى بكيرند، مزمن است، مثل انكيزه

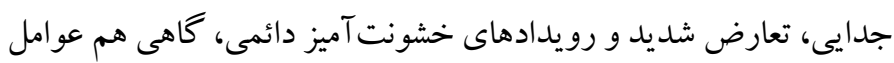
غيره منتظره باعث فروياشى زندكى زناشويى مى شود، مثل افشاء خيانتهاى سهاى زناشويى، و يا موقعى كه يكى از همسر ان قصد جدايى داشته باشد و نسبت

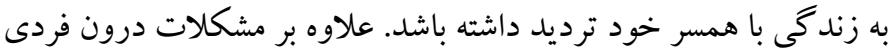




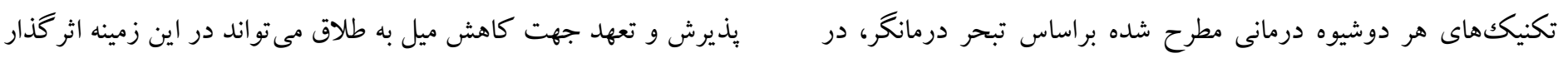

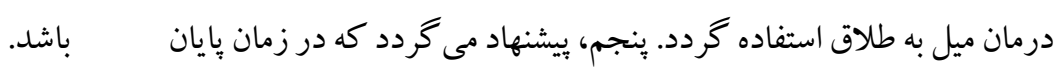
ملاحضات اخلاقى بيروى از اصول اخلاق بثوهش: اين مقاله بر خرفته از رسال دكترى نويسنده اول و

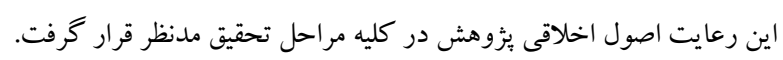
حامى مالى: اين يثوهش در قالب رساله دكترى و بدون حمايت مالى مى باشد. نقش هر يكك از نويسند دوم نويسنده مسئول و استاد راهنما و نويسنده سوم اساتيد مشاور رسال مىباشند. تضاد منافع: نو يسند كان هيج تضاد منافعى در رابطه با اين يُزوهش اعلام نمىنمايند.

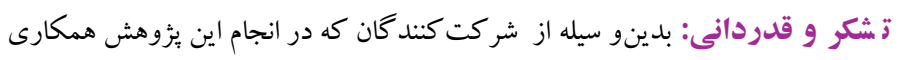
نمودند، تشكر و قدردانى مى گردد.

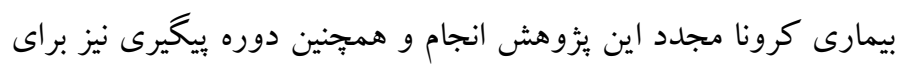

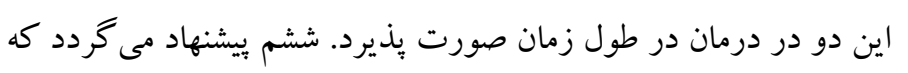

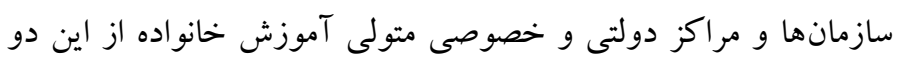

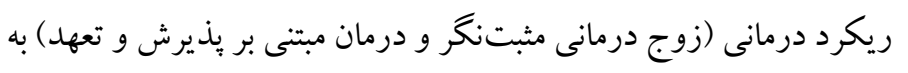

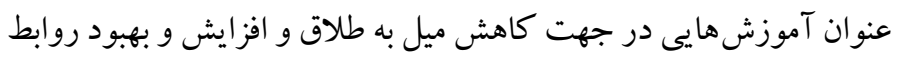
زناشويى مناسب در كلاسهاى مخصوص قبل از ازدواج استفاده نمايند.

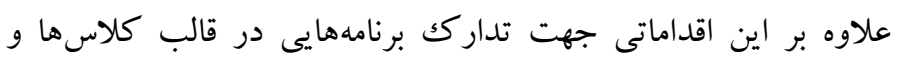

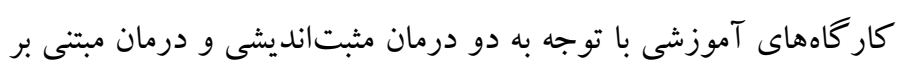




\section{References}

Adabi, M., Hajiha, A., \& Khorshidi, A. (2020). Designing and evaluating organizational happiness pattern of professors of Islamic azad university of Tehran branches (combined study). Journal of psychologicalscience, $\quad$ 19(94), 1291-1306. (Persian). [Link]

Aspara, J., Wittkowski, K., \& Luo, X. (2018). Types of intelligence predict likelihood to get married and stay married: Large-scale empirical evidence for evolutionary theory. Personality and Individual Differences, 122, 1-6. [Link]

Boertien, D., \& Mortelmans, D. (2018). Does the relationship between personality and divorce change over time? A cross-country comparison of marriage cohorts. Acta Sociologica, 61(3), 300-316. [Link]

Brown, F. L., Whittingham, K., Boyd, R. N., McKinlay, L., \& Sofronoff, K. (2015). Does Stepping Stones Triple P plus Acceptance and Commitment Therapy improve parent, couple, and family adjustment following paediatric acquired brain injury? A randomised controlled trial. Behaviour research and therapy, 73, 58-66. [Link]

Flanagan, J. C., Joseph, J. E., Nietert, P. J., Back, S. E., \& McCrady, B. S. (2019). Design of a randomized controlled trial examining the efficacy of oxytocin to enhance alcohol behavioral couple therapy. Contemporary clinical trials, 82, 1-8. [Link]

Halligan, C., Chang, I. J., \& Knox, D. (2014). Positive effects of parental divorce on undergraduates. Journal of Divorce \& Remarriage, 55(7), 557-567. [Link]

Hayes, S. C., \& Lillis, J. (2014). Acceptance and commitment therapy process. In G. R. VandenBos, E. Meidenbauer, \& J. Frank-McNeil (Eds.), Psychotherapy theories and techniques: A reader (pp. 11-17). American Psychological Association. [Link]

Hayes, S. C., Strosahl, K. D., \& Wilson, K. G. (2012). Acceptance and commitment therapy: The process and practice of mindful change (2nd ed.). Guilford Press. [Link]

Jungaberle, H., Thal, S., Zeuch, A., Rougemont-Bücking, A., von Heyden, M., Aicher, H., \& Scheidegger, M. (2018). Positive psychology in the investigation of psychedelics and entactogens: A critical review. Neuropharmacology, 142, 179-199. [Link]

Kloos, N., Drossaert, C. H., Bohlmeijer, E. T., \& Westerhof, G. J. (2019). Online positive psychology intervention for nursing home staff: A clusterrandomized controlled feasibility trial of effectiveness and acceptability. International journal of nursing studies, 98, 48-56. [Link]

Lev, A., \& McKay, M. (2017). Acceptance and commitment therapy for couples: A clinician's guide to using mindfulness, values, and schema awareness to rebuild relationships. Context Press/New Harbinger Publications. [Link]

Matoff, M. (2018). Circumstances to integrate acceptance and commitment therapy with short-term psychodynamic psychotherapies. Cogent psychology, 5(1), 1-24. [Link]

Morshedi, M., Davarniya, R., Zahrakar, K., Mahmudi, M. J., \& Shakarami, M. (2016). The effectiveness of acceptance and commitment therapy (ACT) on reducing couple burnout of couples. Iranian Journal of Nursing Research, 10(4), 76-87. [Link]

Nielsen, A. C. (2017). Psychodynamic couple therapy: A practical synthesis. Journal of marital and family therapy, 43(4), 685-699. [Link]

Nilsen, S. A., Breivik, K., Wold, B., Askeland, K. G., Sivertsen, B., Hysing, M., \& Bøe, T. (2020). Divorce and adolescent academic achievement: Heterogeneity in the associations by parental education. PloS one, 15(3), e0229183. [Link]

Pourmousa, H., Mohammadifar, M. A., Pesand, S. T., \& Rezaei, A. M. (2018). The effectiveness of intimacy training with cognitive-behavioral approach on couples' life quality and happiness. Electronic Journal of General Medicine, 15(6), em95. [Link]

Quinlan, E., Deane, F. P., \& Crowe, T. (2018). Pilot of an acceptance and commitment therapy and schema group intervention for mental health carer's interpersonal problems. Journal of contextual behavioral science, 9, 53-62. [Link]

Rusbult, C. E., Johnson, D. J., \& Morrow, G. D. (1986). Predicting satisfaction and commitment in adult romantic involvements: An assessment of the generalizability of the investment model. Social Psychology Quarterly,49(1), 81-89. [Link] 
Samadi, H., Doostkam, M. (2017). Investigating the effectiveness of Acceptance and Commitment Therapy (ACT) on marital compatibility in infertile women, Thought and Behavior in Clinical Psychology, 11(43), 67-76. [Link]

Seligman, M. E., \& Csikszentmihalyi, M. (2014). Positive psychology: An introduction. In Flow and the foundations of positive psychology (pp. 279-298). Springer, Dordrecht. [Link]

Seligman, M. E., Ernst, R. M., Gillham, J., Reivich, K., \& Linkins, M. (2009). Positive education: Positive psychology and classroom interventions. Oxford review of education, 35(3), 293-311. [Link]

Sianturi, R., Keliat, B. A., \& Wardani, I. Y. (2018). The effectiveness of acceptance and commitment therapy on anxiety in clients with stroke. Enfermeria Clinica, 28, 94-97. [Link]

Szarkowski, A., \& Brice, P. (2018). Positive psychology in research with the deaf community: An idea whose time has come. The Journal of Deaf Studies and Deaf Education, 23(2), 111-117. [Link]

Yip, F. W., Zelman, D., \& Low, A. (2019). How to improve parenting in Hong Kong by training: the 6As Positive Parenting Program. Public Administration and Policy, 22(1), 55-70. [Link] 